\title{
Gingival esthetics: An orthodontic and periodontal approach
}

\author{
Máyra Reis Seixas', Roberto Amarante Costa-Pinto², Telma Martins de Araújo³
}

Introduction: Currently, people's esthetic requirements and expectations have increased substantially. Therefore, dentists have been seeking ways to provide excellent treatment results which, consequently, increasingly require a well organized transdisciplinary approach. The link between orthodontics and periodontics became evident from the moment professionals began to understand the biology of tooth movement. As regards smile esthetics, however, such cooperation is now essential. Objective: To show clinically how and when orthodontists and periodontists should work jointly to enhance smile esthetics based on the display and harmony of the gingival contour.

Keywords: Orthodontics. Smile. Esthetics. Periodontics.

Introdução: nos dias atuais, as expectativas e exigências estéticas das pessoas têm aumentado substancialmente. Por isso, a Odontologia vem buscando maneiras de oferecer tratamentos com resultados excelentes e, consequentemente, necessita trabalhar, cada vez mais, de modo transdisciplinar. A inter-relação da Ortodontia com a Periodontia é evidente desde quando se compreendeu a biologia da movimentação dentária; contudo, em se tratando de estética do sorriso, tornou-se fundamental. Objetivo: evidenciar, clinicamente, como e quando a Ortodontia e a Periodontia devem trabalhar de modo integrado para a obtenção de sorrisos mais estéticos, considerando-se a exposição e a harmonia do contorno gengival.

Palavras-chave: Ortodontia. Sorriso. Estética. Periodontia.

\section{INTRODUCTION}

In the recent past, orthodontists placed less emphasis on periodontal health and the esthetic appearance of the gums when finishing treatment. They believed that aligning and leveling the teeth was sufficient to ensure positive results, and often overlooked the fact that smile esthetics depends on a number of factors, among which are the display

${ }^{1}$ MSc in Orthodontics, UFRJ. Professor, Specialization Program in Orthodontics, UFBA. Diplomate by the Brazilian Board of Orthodontics and Facial Orthopedics (BBO).

\footnotetext{
${ }^{2}$ MSc in Orthodontics, UFRJ. Professor of Orthodontics, EBMSP. Professor, Specialization Program in Orthodontics, UFBA.

${ }^{3} \mathrm{MSc}$ and PhD in Orthodontics, UFRJ. Head Professor and Coordinator, Prof. José Édimo Soares Martins Center of Orthodontics, UFBA. Past President, Brazilian Board of Orthodontics and Facial Orthopedics.
}

» Patients displayed in this article previously approved the use of their facial and intraoral photographs. and architecture of apparent gingival tissue and its contour, phenotype, zenith position and presence of interdental papilla. ${ }^{1,2,3}$

Furthermore, the number of adult orthodontic patients has grown considerably. Although more compliant with treatment than adolescents, adults pose a host of challenges to the orthodontist: They may have missing, worn or abraded teeth, uneven

How to cite this article: Seixas MR, Costa-Pinto RA, Araújo TM. Gingival esthetics: An orthodontic and periodontal approach. Dental Press J Orthod. 2012 SeptOct;17(5):190-201.

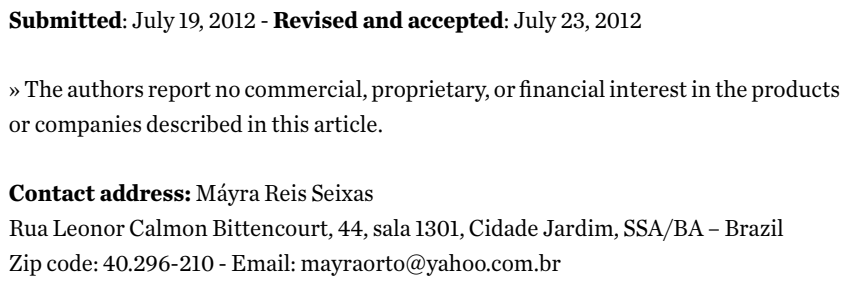



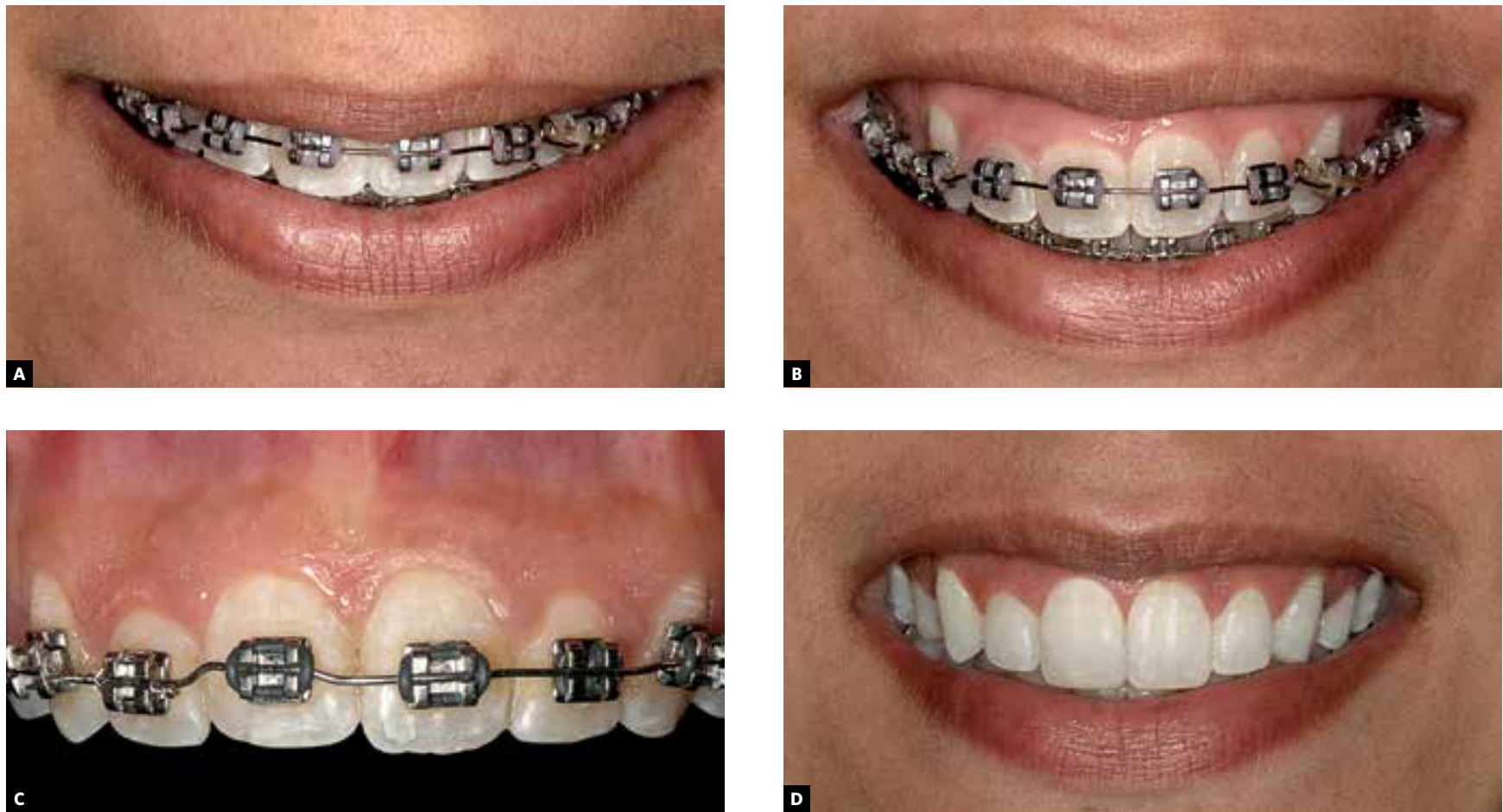

Figure 1 - A, B) Smile esthetics affected by disharmonious gingival contours although anterior teeth look well aligned and leveled. C, D) Improved gingival contour after periodontal surgery and orthodontic movement. Gingivectomies were performed on teeth \#12 and 21, as well as intrusion of \#11 with subsequent restoration of its incisal edge. During orthodontic intrusion, tooth \#11 moved apically, carrying with it the entire periodontium, while maintaining biological distances.

gingival margins, loss of bone and interdental papillae. Finally, problems that can undermine the esthetic appearance of the teeth after debracketing. Given the complexity of these treatments, the increased choice of therapeutic resources, and increased esthetic demand by patients, a transdisciplinary approach in orthodontic treatment is now paramount, and an integration with periodontists, an absolute must ${ }^{4-10}$ (Fig 1).

Periodontic concepts have also evolved. Recent advances in basic science in the field of periodontal biology along with clinical trials in the prevention and treatment of periodontal disease have shifted dramatically the focus of periodontal treatments. In view of a lack of direct correlation between probing depth and the presence or absence of active disease, eliminating periodontal pockets is no longer the only goal of periodontal therapy. The indiscriminate use of resective procedures common until the mid-1980s generated undesirable sequelae in tissue architecture, such as gingival margin recession and potential loss of interdental papillae $^{10,11}$ (Fig 2). Additionally, the search for better and more effective alternatives to rebuild tissue loss during disease progression and after resective procedures ${ }^{2,3}$ represented a great leap for periodontics in the pursuit of "red esthetics" and quality of life for patients.

This realization underscores the increasing need for exchange of information and scientific knowledge between orthodontists and periodontists. It is therefore necessary that the theoretical and practical training of these professionals converge.

\section{IDEAL GINGIVAL ESTHETIC CONTOUR}

The appearance of the gingival contour follows the underlying bone architecture and is influenced primarily by factors such as tooth position, type of periodontium, tooth form, and design of the CEJ. In a clinically healthy periodontium, the gingival contour forms and invests the CEJ., ${ }^{2,3,13}$

The contour of the gingival margins of the six maxillary anterior teeth plays an important role in smile esthetics and is determined by the 

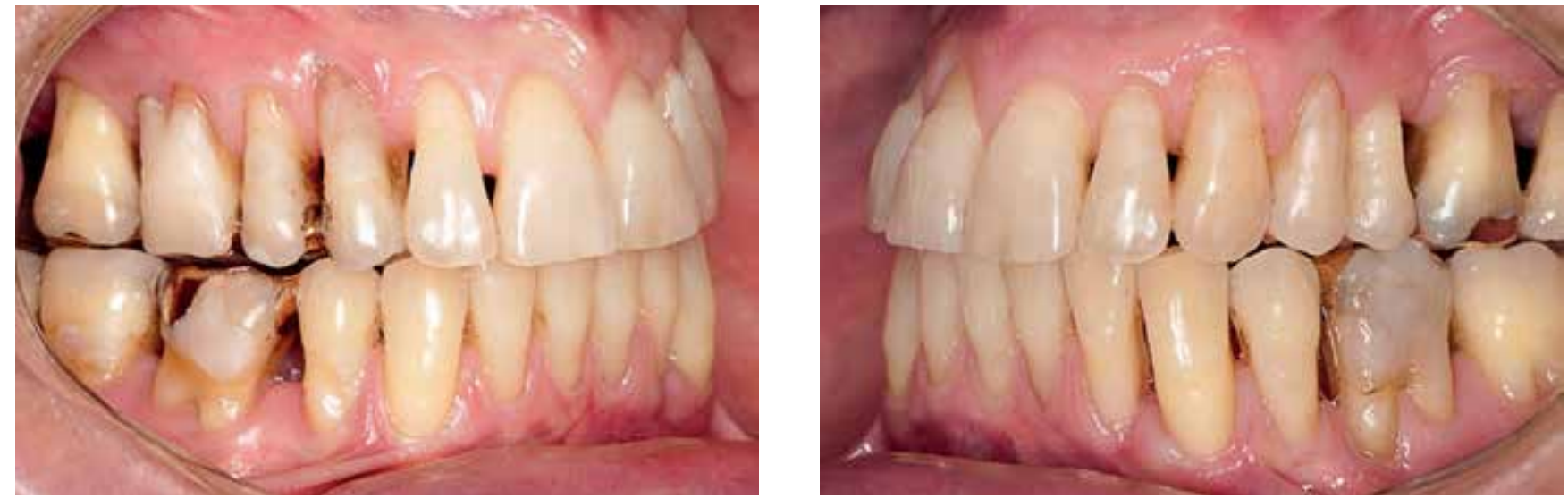

Figure 2 - Undesirable sequelae in a female patient's periodontium treated by resective surgical procedures.

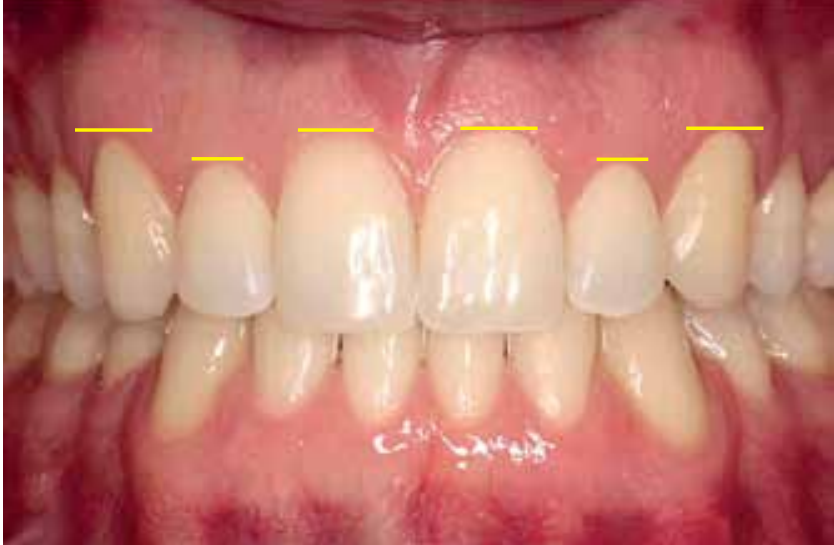

Figure 3 - Differences between the heights of the apical gingival margins of anterior teeth, determining the ideal gingival contour for the region.

following features: Firstly, the gingival margins of the central incisors should be on the same level, furthermore, they should position themselves more apically to the margins of the lateral incisors and remain on the same level of the margins of the canines. The contour of the gingival margins must coincide with the CEJs of the teeth, and each tooth must have a gingival papilla that occupies the interdental embrasure (Fig 3).

According to a study published by Kokich, ${ }^{14}$ the closer to the midline gingival contour asymmetries are located, the more easily these asymmetries will be identified as less esthetic by orthodontists, GPs and laypersons alike. Therefore, there may be variations in the patterns described above when these are located in different quadrants of the same patient, but contour symmetry between central incisors is always necessary. One might add that when the height of the gingival margin of the lateral incisors is positioned more than $2 \mathrm{~mm}$ above the gingival margin of the central incisors and canines, smile esthetics is said to be compromised (as shown in the description of Fig 9). Kokich also suggests that patients with gingival contour discrepancies and low smile line require no correction as this condition is not seen as esthetically relevant. ${ }^{6-10}$

Interdental papillae form the gingival tissue that fills the space between adjacent teeth. These papillae are influenced by the distance and inclination between teeth, alveolar bone height and anatomical form of clinical crowns, with the latter determining interproximal contact point height ${ }^{2,3}$ (Fig 4).

Papillae can be observed in regions at a distance of less than or equal to $5 \mathrm{~mm}$ between the alveolar bone crest and the contact point. When this value is increased to $6 \mathrm{~mm}$ or $7 \mathrm{~mm}$, the ability to observe the papilla is hindered, while measurements above $7 \mathrm{~mm}$ often mean that the papilla is not present ${ }^{15}$ (Fig 5).

Distances of less than $0.3 \mathrm{~mm}$ between roots result in a reduction of the proximal bone, a condition often accompanied by an absence of interdental papilla. Moreover, large interradicular spaces, e.g., diastemas, are usually associated with short, flattened papillae. ${ }^{16}$

The loss of the papillae as a sequela of periodontal disease or iatrogenic dental procedures causes 

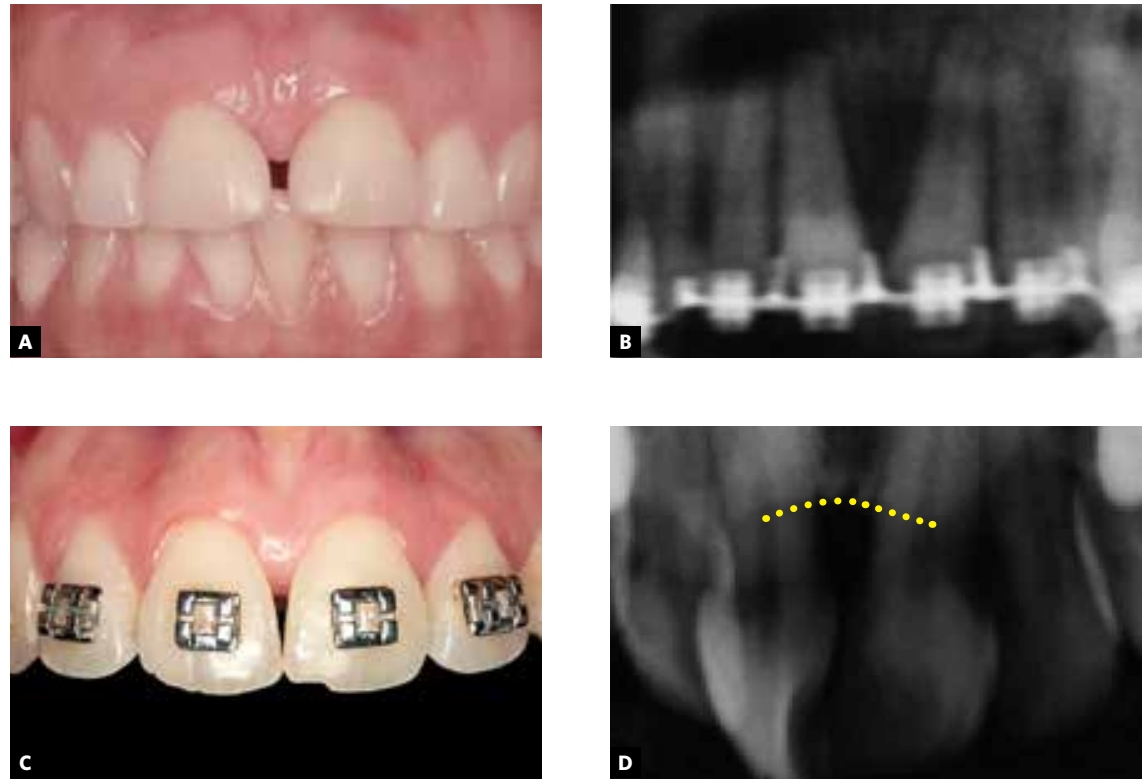

Figure 4 - Factors determining the presence and form of the papillae: $\mathbf{A}, \mathbf{B}$ ) Distance and inclination between the teeth; (D) triangular form of the clinical crown, (C) alveolar bone crest height.
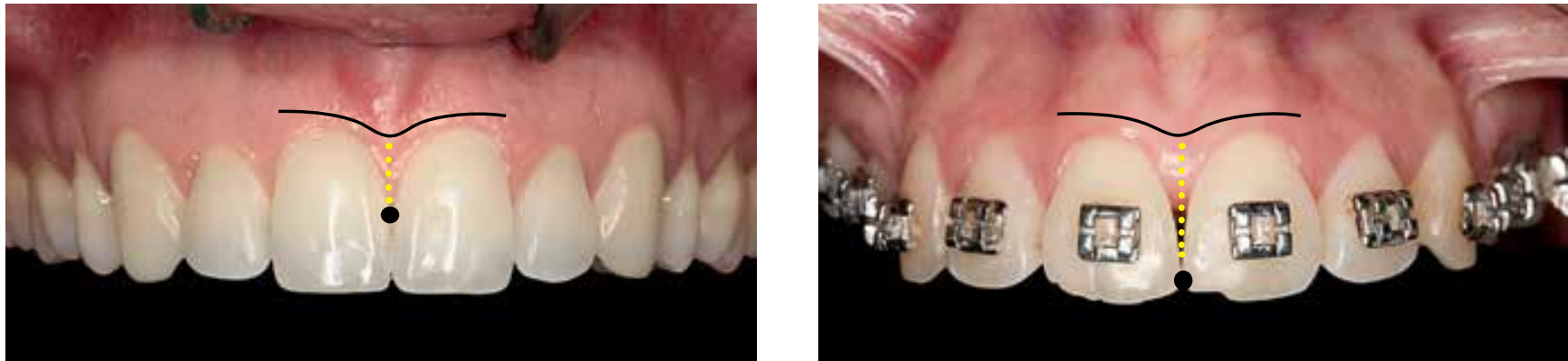

Figure 5 - Relationship between the presence of interdental papillae, and the distance between the alveolar bone crest and the contact point of the teeth.
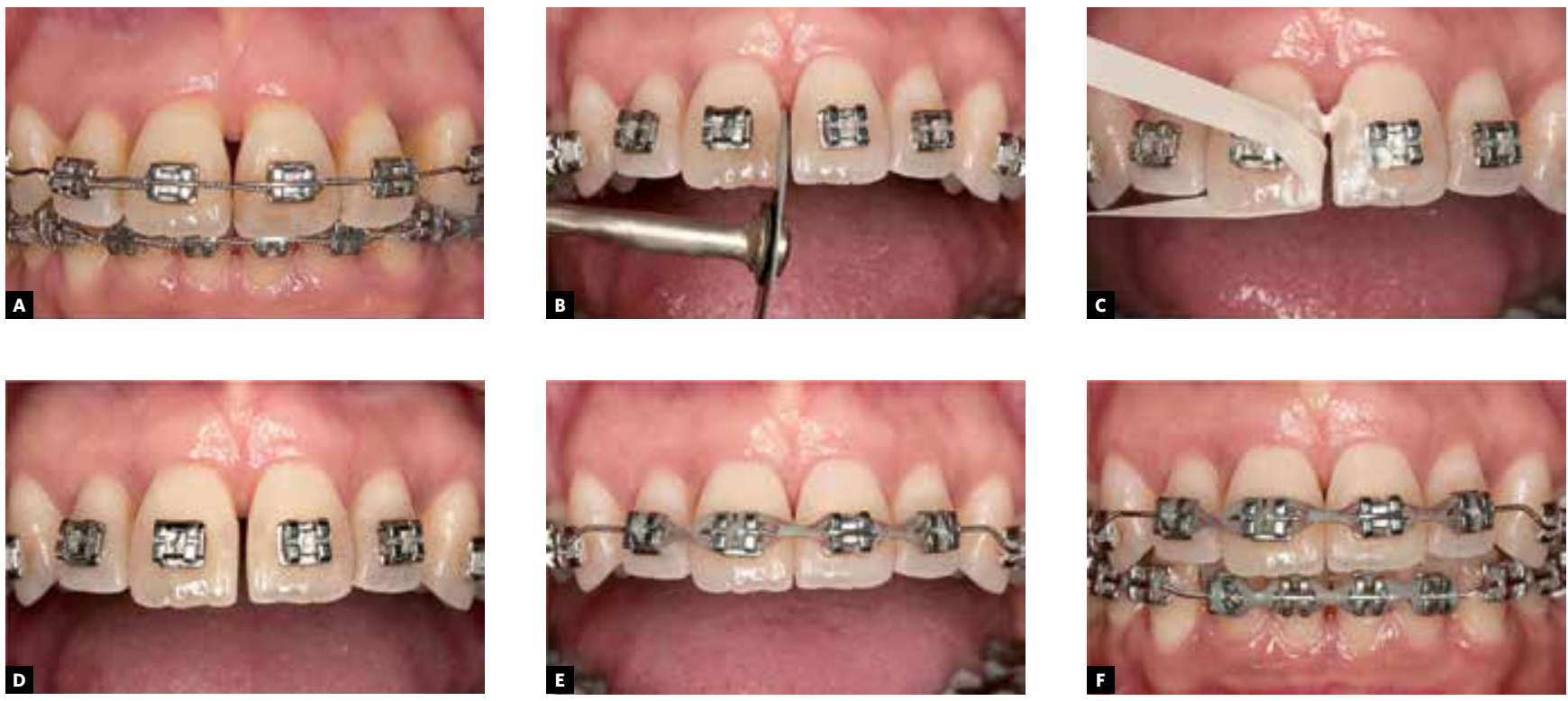

Figure 6 - A) Median dark space caused by alveolar bone crest loss B) Interproximal stripping performed with diamond steel disk at low rotation; C) polishing of the stripped surfaces with flexible strips of sandpaper and whiting $\mathbf{D}$ ) space created between incisors; $\mathbf{E}, \mathbf{F})$ bringing teeth closer together with elastomeric chains, showing improvement in papillary esthetics. 
the formation of "dark spaces" that interfere negatively in the perception of smile esthetics. The small size of interdental papillae combined with a purely capillary nutrition render their reconstruction a periodontal procedure whose outcome is hard to predict, further strengthening the idea that papillae should be carefully preserved. ${ }^{2,3}$ Orthodontists treat this condition by combining interproximal stripping with tooth movements, and positioning more apically the contact point between the teeth (Fig 6). Soft tissue grafts can improve tissue volume, but in most cases results only give a misleading impression that the dark space has been reduced or closed since the height of the papillae is not completely restored., ${ }^{2,3}$

\section{DISCREPANCIES IN GINGIVAL ESTHETIC CONTOURS}

Changes in gingival contour may be located either coronally or apically relative to CEJ, and can be addressed in various manners, by:

» Orthodontic movement, intruding or extruding the teeth involved ${ }^{1,7,8,9}$

» Resective gingival surgery to lengthen the clinical crown (gingivectomy or gingivoplasty)

» Resective bone surgery to lengthen the clinical crown

Planning and selecting the best option to correct the problem depends on several factors: Sulcus depth on probing, location of CEJ relative to the bone level, crown-root relationship between the teeth involved, root form, ${ }^{1,2,3}$ and degree of gingival display on smiling. ${ }^{18}$

The conditions listed below adversely affect the harmony of the gingival contour and their respective treatment options.

\section{Compensatory dental extrusion}

Compensatory dental extrusion is one of the conditions that alter the gingival contour. It tends to occur as a result of wear and/or fracture of the incisal edge of anterior teeth, which extrude and carry with them the entire periodontal tissues. It affects adult patients who usually present with poor horizontal and vertical relationship between the dental arches. In these cases, the anterior teeth extrude and carry with them the periodontal tissues. Clinical examination disclosed incisors with normal probing depths and worn incisal edges, causing an esthetically inadequate width/ height ratio, which is usually these patients' chief complaint. ${ }^{7-10}$

There are two treatment options which should be discussed with the patient:

1) Clinical crown lengthening surgery with osteotomy. The main objective of this procedure is to restore clinical crown height lost at the expense of marginal periodontal tissue by means of resective techniques and apical repositioning. The main disadvantage of this approach is a reduction in dental implantation due to a decrease in the root/crown ratio, given root surface exposure and the need for additional restorative treatment. ${ }^{2,3}$ Moreover, since roots have a tapered form, satisfactory interproximal esthetics cannot be ensured, and it is not uncommon to find poor sealing of the embrasures and the emergence of "dark spaces" postoperatively. Filling these gaps with restorative materials creates the appearance of wide, "square" teeth in addition to an irregular emergence profile with an exceedingly convex tooth/ restoration interface, which hampers biofilm control and can compromise the health of the periodontium.

2) Orthodontic leveling of the gingival margins and subsequent restoration of the incisal portion of the teeth: The key purpose of this approach is to level the CEJ. This procedure is more conservative and biological but requires the use of a fixed orthodontic appliance and longer treatment and retention times (Fig 7).

Currently, the placement of a fixed appliance in patients whose anterior teeth have their incisal edges worn and/or fractured should be performed by taking as reference the gingival margin positioned more apically ${ }^{7-10}$ (Fig 8).

Given that the primary objective of the approach in these cases is to level the gingival contour, the clinical and radiographic evaluation of the patient prior to treatment should be implemented to verify periodontal health, shallow levels of gingival sulci, and particularly, similar values (Figs 9 and 10). 

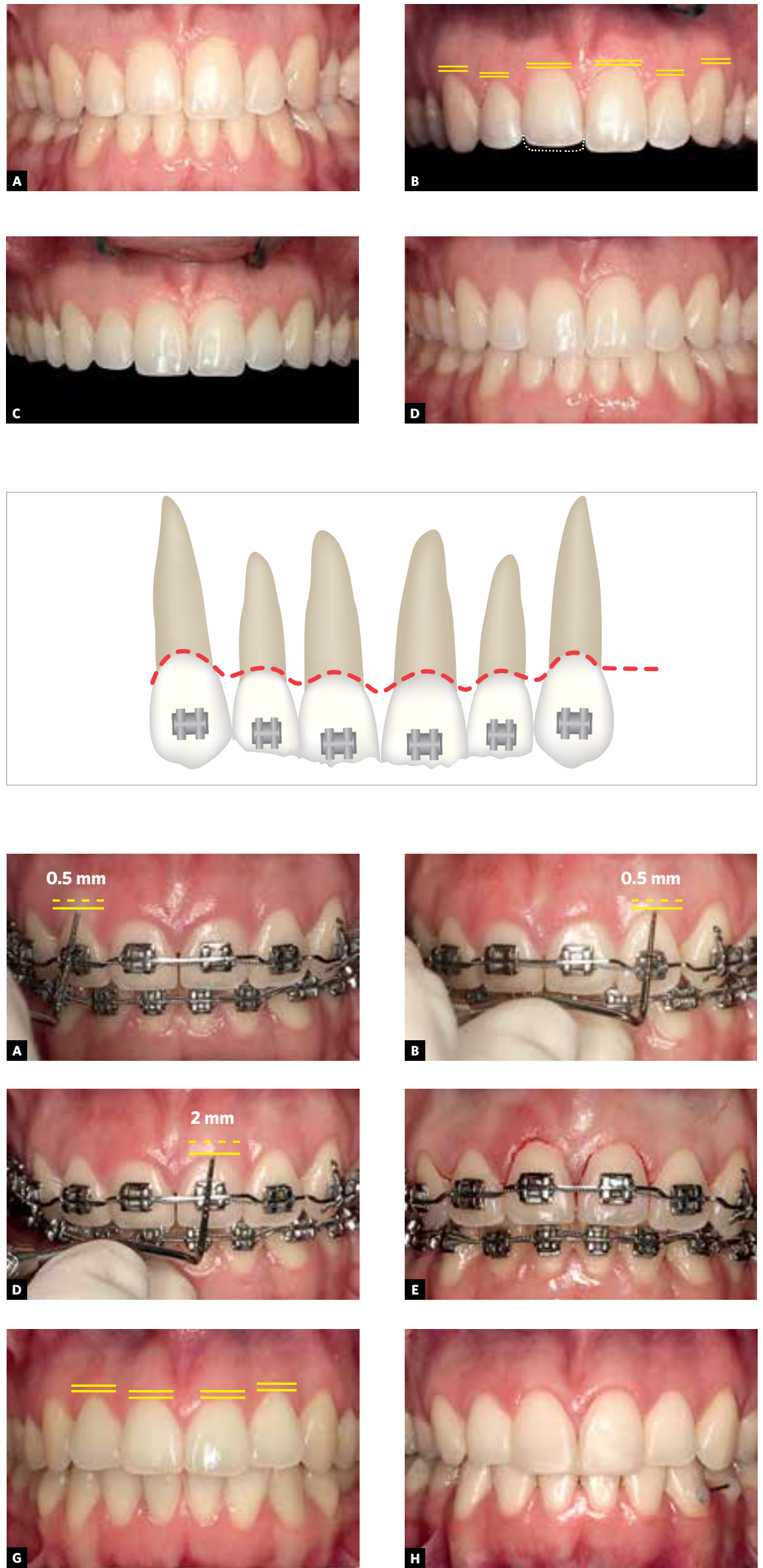
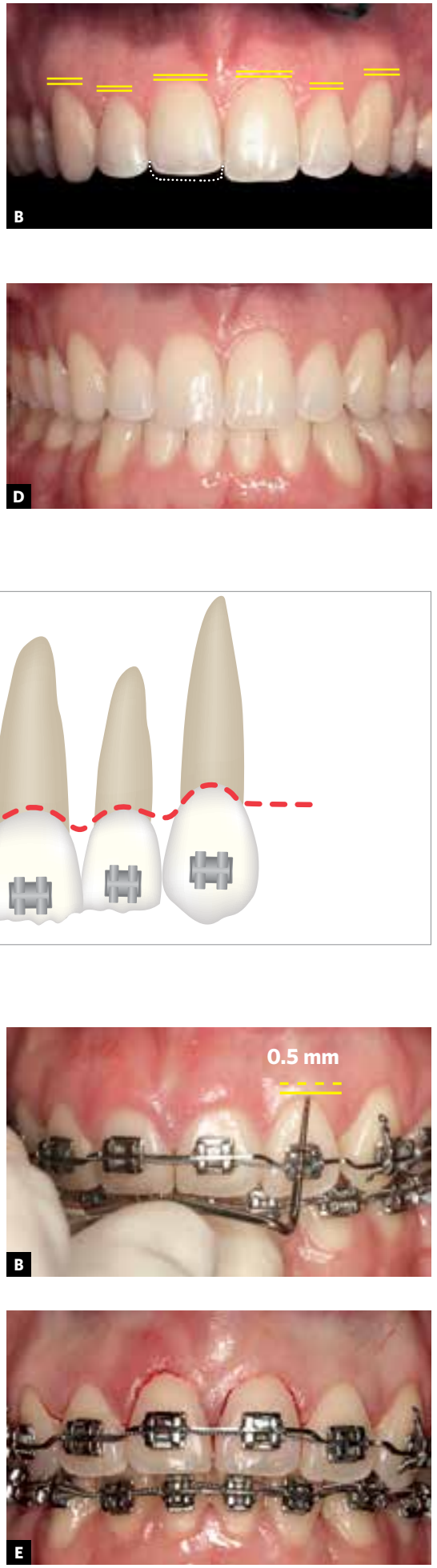

Figure 7 - A) Case finished with harmonious gingival contour; B) minimal, similar probing depths, and uneven incisal silhouette due to incisal edge wear of tooth \#11; C, D) restoration of incisal edge of \#11 with composite resin

E) properly balanced incisal guidance.

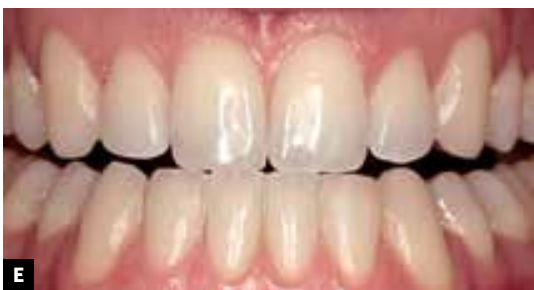

Figure 8 - Orthodontic appliance placed on anterior teeth with irregular incisal edges due to wear and/or fracture: In the event that gingival contours are found to be uneven, and the depth of gingival sulci are minimal and similar, bonding of orthodontic brackets should use as reference the apical height of the gingival margin, which constitutes the CEJ of the teeth.
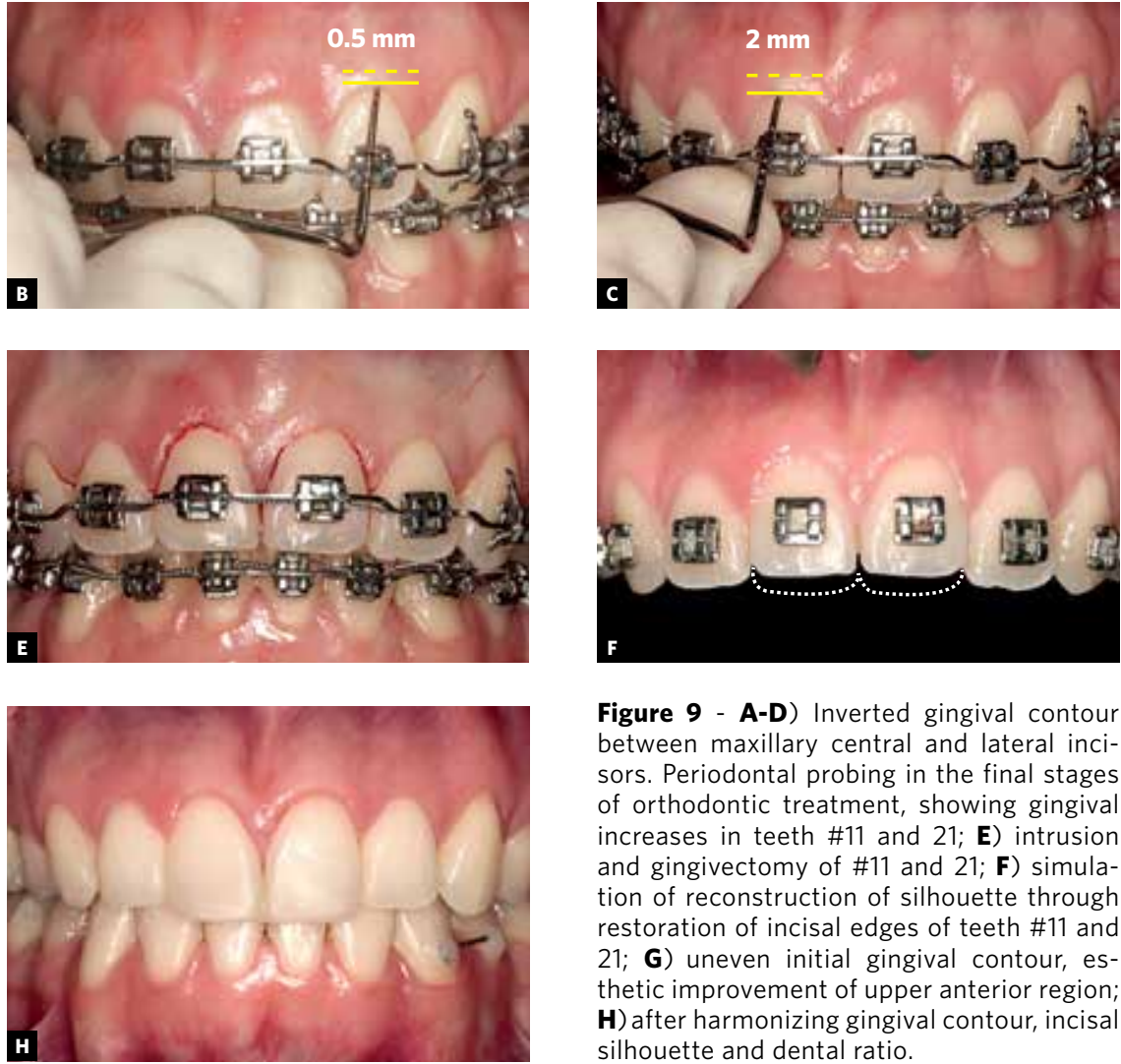

Figure 9 - A-D) Inverted gingival contour between maxillary central and lateral incisors. Periodontal probing in the final stages of orthodontic treatment, showing gingival increases in teeth \#11 and 21; E) intrusion and gingivectomy of \#11 and 21 ; F) simulation of reconstruction of silhouette through restoration of incisal edges of teeth \#11 and 21 ; G) uneven initial gingival contour, esthetic improvement of upper anterior region H) after harmonizing gingival contour, incisal silhouette and dental ratio. 

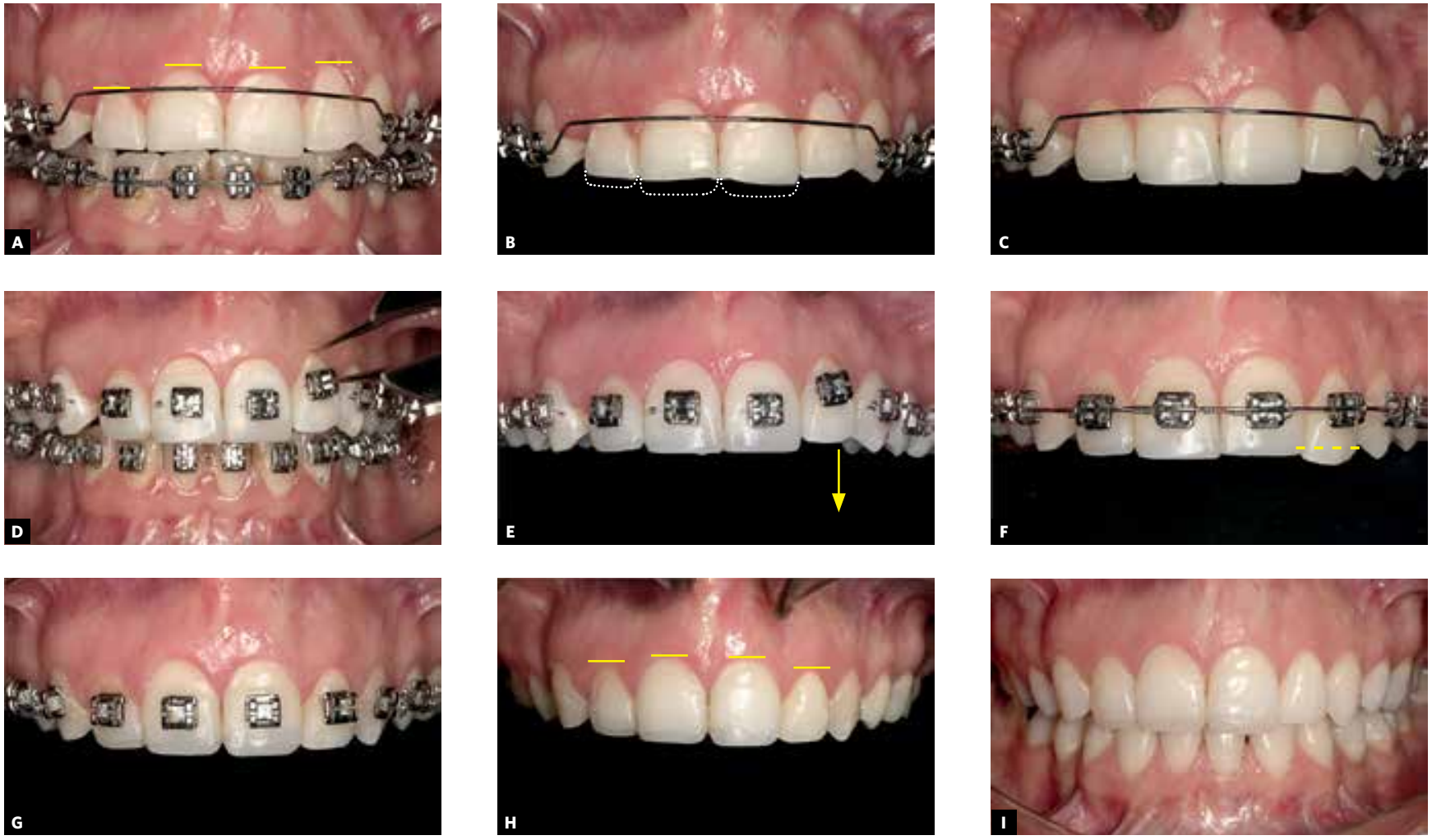

Figure 10 - A, B) Patient nearing completion of orthodontic treatment, showing uneven gingival contour in upper anterior region, and wear of incisal edges of teeth \#12, 11 and 21; C) provisional composite resin restorations established a new incisal silhouette and new anatomical proportions for these teeth; D) rebonding of brackets taking as reference the apical gingival margin of incisors; E, F) leveling of gingival margins of upper anterior region by extrusion and ameloplasty of tooth \#22; $\mathbf{G}, \mathbf{H}, \mathbf{I})$ final esthetic appearance after dentogingival leveling of the case.

\section{Altered passive eruption}

The normal tooth eruption process is considered complete when the teeth reach the occlusal plane and go into function. The soft tissues, in turn, follow this movement and ultimately the gingival margin migrates apically almost as far as the CEJ. When this does not happen and the gingiva continues to invest part of the dental clinical crown, it is named altered passive eruption (APE). ${ }^{2,13}$

APE cases usually involve young patients presenting with intact anterior incisal edges and undesirable width/height dimensions. The orthodontist is responsible for properly diagnosing this condition and treatment planning should invariably involve cooperation by a periodontist to ensure gingival esthetics ${ }^{17}$ (Fig 11).

According to Garber and Salama, ${ }^{17}$ APE can be classified based on the amount of keratinized gingiva: Type 1: Wide band of keratinized gingiva; Type 2: Narrow band of keratinized gingiva, and also subclassified according to the relationship between the CEJ and alveolar bone crest:

» Subgroup A: The distance between the alveolar bone crest and the CEJ is greater than or equal to $1 \mathrm{~mm}$, therefore sufficient for the connective tissue attachment. In this subgroup, in type I cases, gingivectomy can solve the problem, while in Type II cases, a flap displaced apically is indicated.

» Subgroup B: The distance between the alveolar bone crest and the CEJ is less than $1 \mathrm{~mm}$, therefore insufficient for the connective tissue attachment. In these cases, osteotomy is necessary to establish correct biological distances. Therefore, the distance from the alveolar bone crest to the CEJ determines whether or not there it is necessary to displace the flap in order to remodel the bone, ensuring sufficient space to accommodate the connective tissue attachment. 

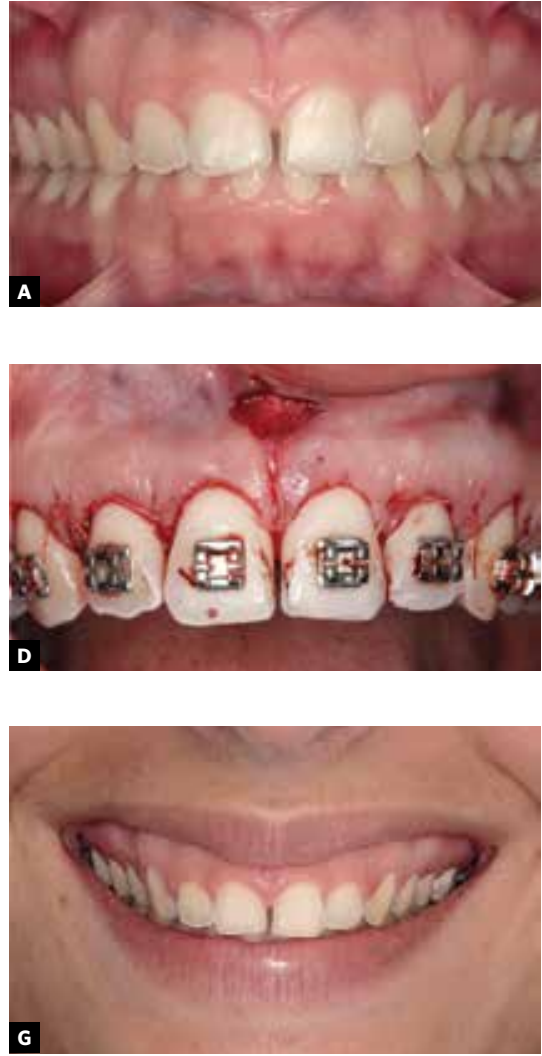
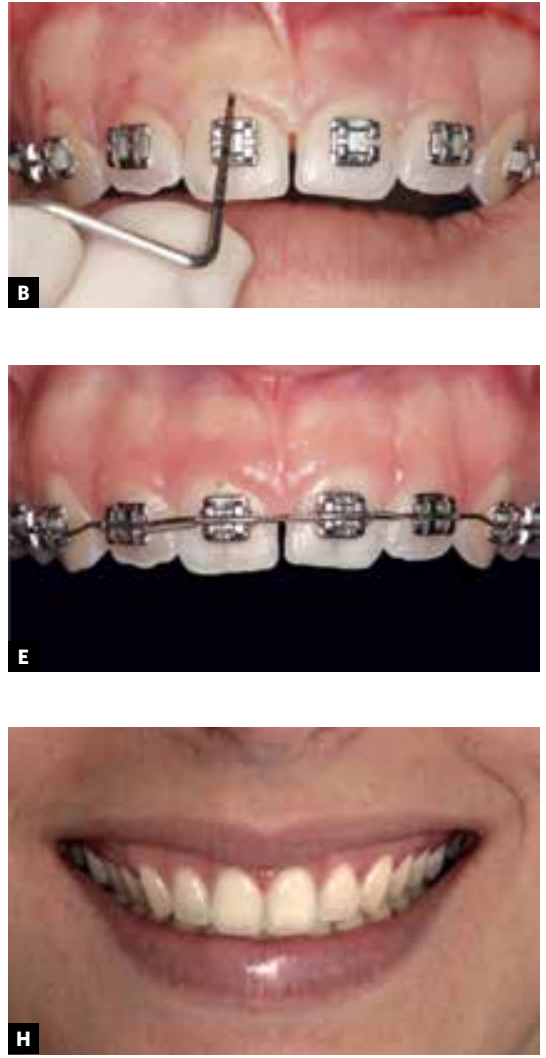
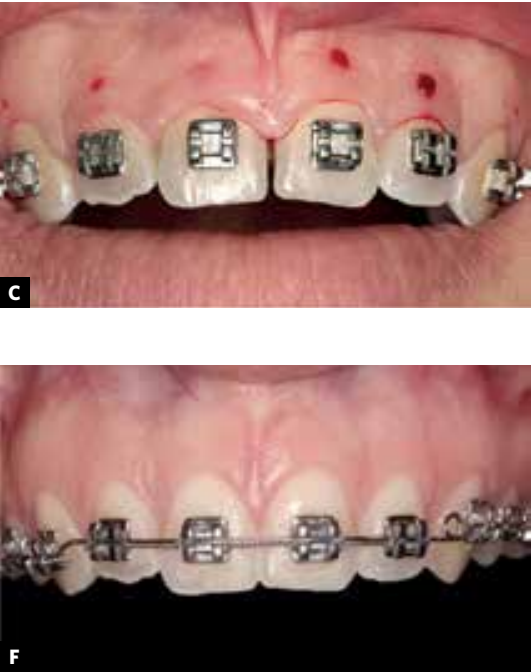

Figure 11 - A) Altered passive eruption: Reduced size of incisor crowns, B, C) immediately after starting orthodontic treatment periodontal probing disclosed gingival enlargement in upper anterior region; D) clinical crowns enlarged by means of gingivectomy E, F) changes effected in gingival contour and dimension of clinical crowns of upper anterior teeth; G, H) improved smile esthetics.
This classification is important when choosing the periodontal therapy to be employed in each case specifically.

Many patients present with APE in all anterior teeth and their chief complaint is excessive gingival display on smiling, which characterizes "gummy smile." When there is a combination of vertical maxillary excess in its etiology - which would require ortho-surgical treatment - these issues can be fully addressed with periodontal surgery (clinical crown lengthening), with a considerable impact on smile esthetics and on patient satisfaction with the treatment outcome ${ }^{18}$ (Fig 11).

Many patients often find it difficult to maintain proper oral hygiene during the course of orthodontic treatment. Moreover, given the presence of orthodontic brackets, a reduction occurs in the selfcleaning process effected by the lips and cheeks, also contributing to the emergence of gingival inflammation, with isolated or widespread increases in probing depths. Regardless of how satisfactorily one succeeds in leveling and aligning the teeth, and in achieving functional occlusion, smile esthetics is never entirely satisfactory after removal of the orthodontic appliance.

Often, however, one can restore oral hygiene to optimum levels after appliance removal, thereby reducing gingival enlargement in these cases. Thirty to sixty days after removal of the orthodontic appliance, should gingival enlargement persist in some regions, the periodontist should intervene surgically to correct these pseudo pockets.

\section{Gingival recession}

Gingival recession is defined as the apical migration of the gingival margin toward the CEJ. It can affect individual teeth or groups of adjacent teeth. It can also be associated with other factors such as: Noncarious cervical lesions, cervical dentinal hypersensitivity, abfraction, and increased 
biofilm accumulation. This condition is a frequent complaint among patients, and adversely affects gingival contour esthetics by rendering it less attractive. ${ }^{2,13}$

The negative correlation between orthodontic tooth movement and loss of gingival attachment has been extensively reported. ${ }^{2,12,19-23}$ Often, even prior to orthodontic treatment patients present with a compromised periodontium, and bone dehiscence is usually already present, especially in areas of incisors and canines. This anatomical condition can only be diagnosed and evaluated more accurately by CT scans of these regions. In these cases, orthodontic movement can be performed as usual, but greater care should be exercised regarding biofilm control, in addition to implementing a correct, non-traumatic brushing technique. ${ }^{24}$

When tooth movements are made toward the cortical bone, bone dehiscences may result. ${ }^{19-23}$ This does not mean that in such cases orthodontic movement inevitably entails a loss of attachment, but does indicate that this is more likely to happen in the presence of etiologic factors of gingival recession, i.e.,inflammation caused by biofilm and/ or tooth brushing trauma.

Classical studies in animals ${ }^{14-18}$ showed bone formation in areas of bone dehiscence after tooth movement in medullary directions. According to Lindhe, ${ }^{12}$ in some cases areas of gum recession can also be masked by coronal migration of the soft tissue margin, reflected by increased gingival height (Fig 12).
What is known, however, is that moving teeth in medullary directions often induces bone formation in areas of dehiscence. Tooth movement in these cases appears to be beneficial to periodontal health as it improves the morphology of alveolar bone and decreases anatomical predisposition to tissue attachment loss (Figs 13 and 14). ${ }^{19-23}$

In view of the above, the existence of gingival recession prior to the start of orthodontic treatment will require periodontal surgery for root coverage before starting to move teeth that present with gingival recession, especially if these teeth are moved toward the

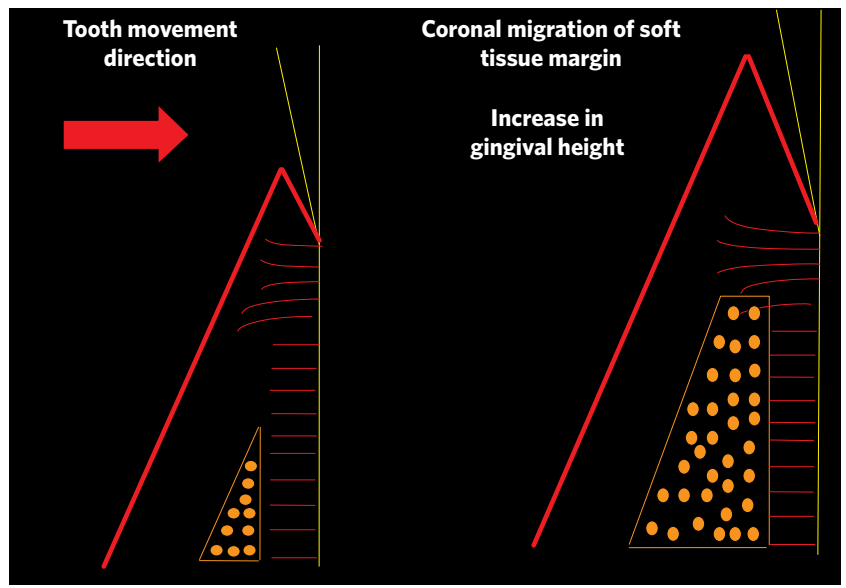

Figure 12 - Changes that occur in marginal periodontal tissues after moving lingually teeth with bone dehiscence positioned labially in the dental arch: Increases in bone and gingival height can be observed, as well as coronal migration of soft tissue margin after movement (Adapted from: Kokich, Kokich, Spear ${ }^{10}$ ).
Figure 13 - Gingival recession and buccal positioning of tooth \#32's root $(\mathbf{A}, \mathbf{B})$; reduced recession after orthodontically moving root to correct position in alveolar bone (C, D).
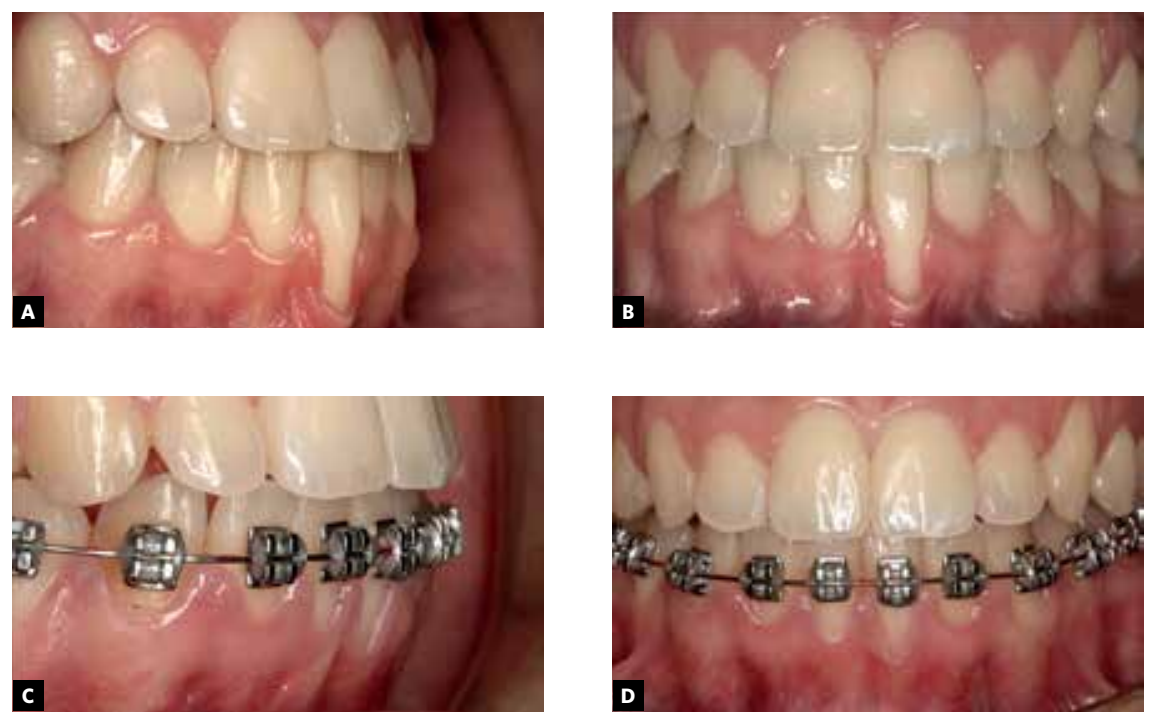

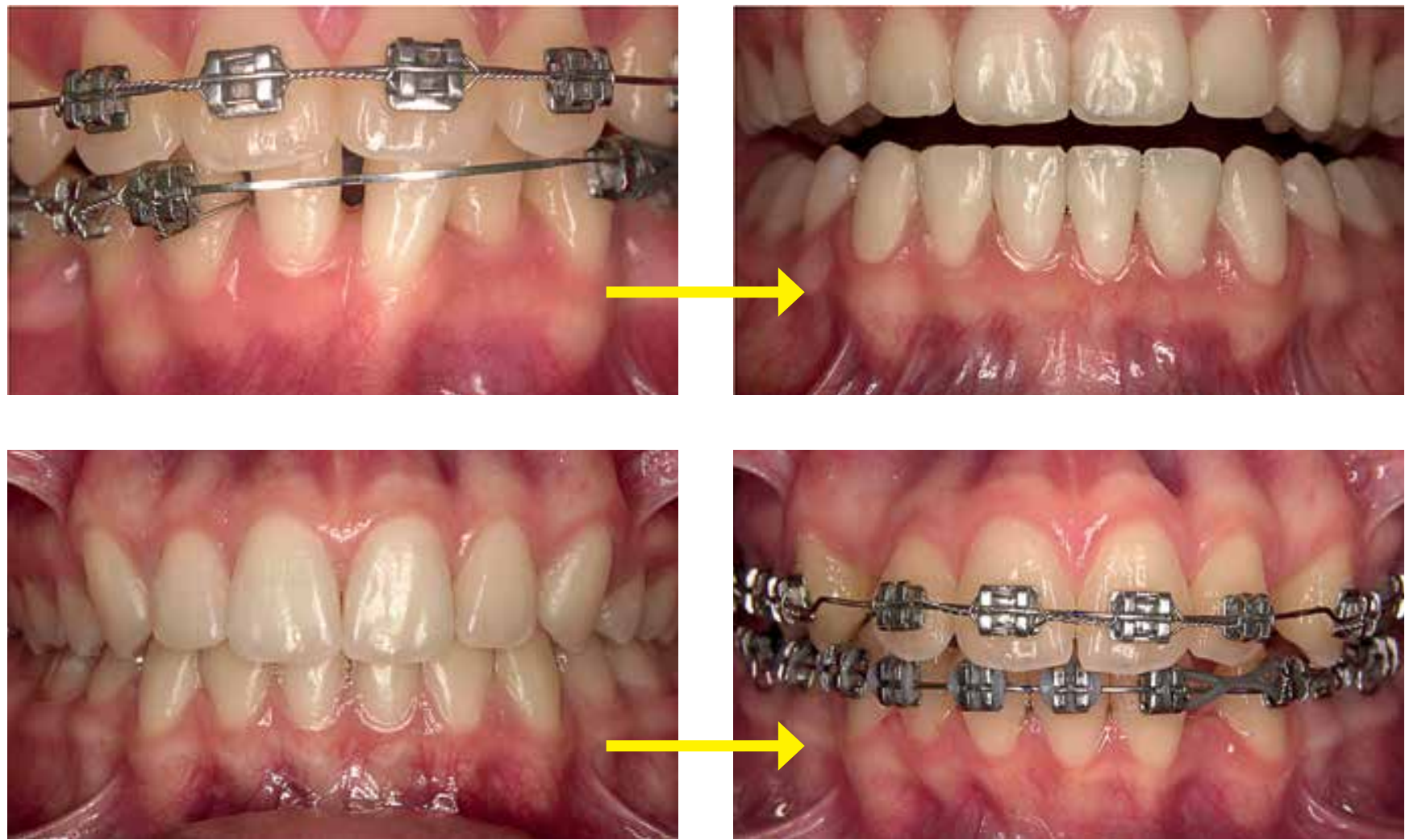

Figure 14 - Patients with unfavorable periodontal phenotypes treated with first premolar extraction and incisor retraction. Changes in alveolar bone morphology can be observed as teeth have taken on a less cortical position. Gingival aspect appeared less distended and slender, and possibly less susceptible to potential trauma and/or inflammatory diseases.
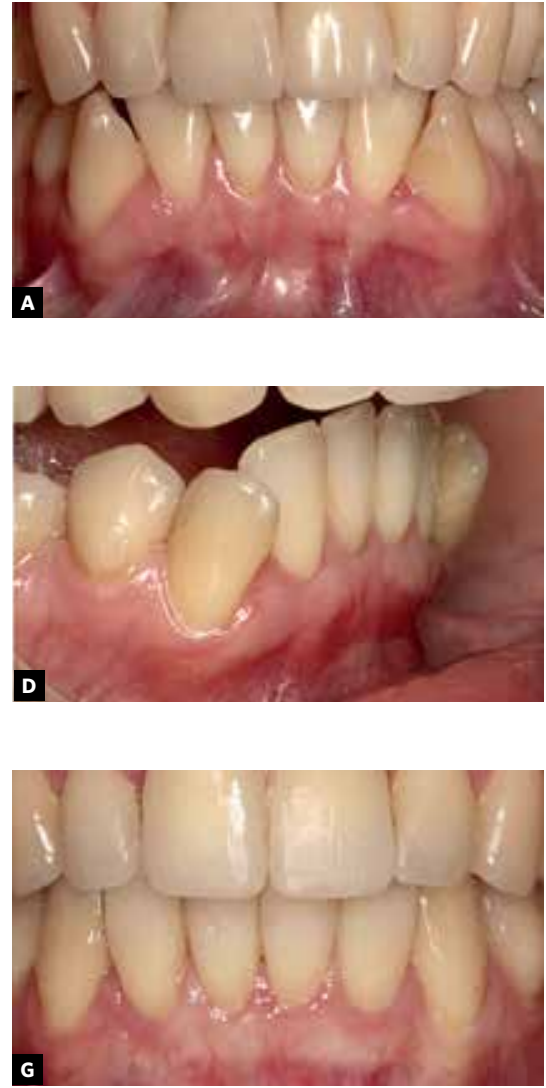
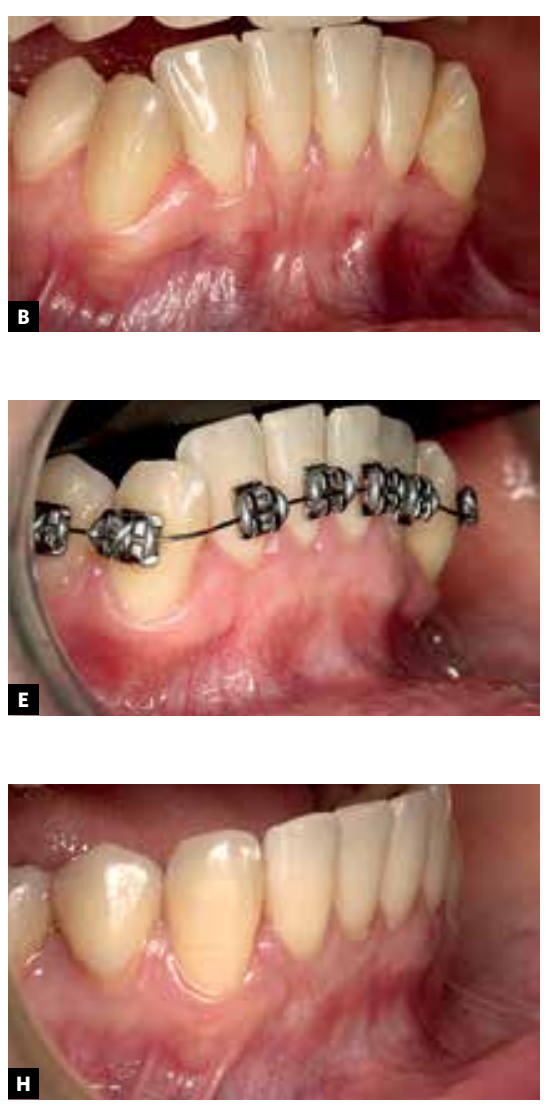
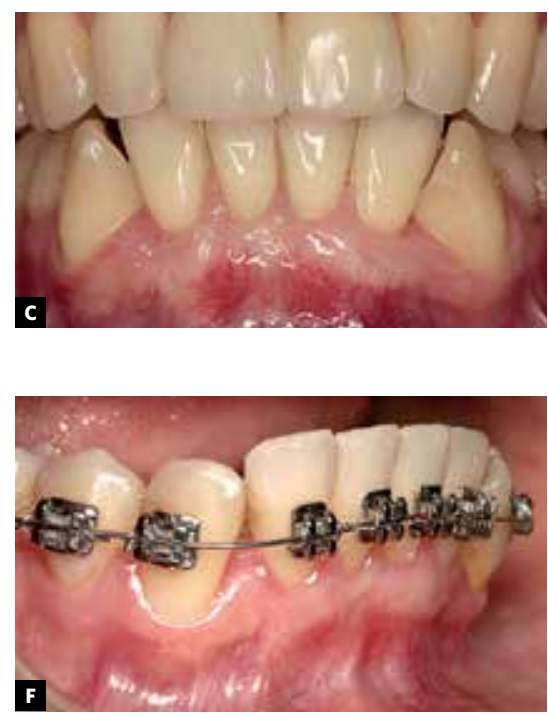

Figure 15 - A, B) Patients with unfavorable periodontal phenotype and gingival recession on buccal region of lower incisors, which need to be moved labially; C, D) gingival area coverage before starting orthodontic movement: E, F) proclination of lower incisors toward covered region without worsening preexisting condition; $\mathbf{G}, \mathbf{H})$ gingival integrity at the end of orthodontic treatment. 

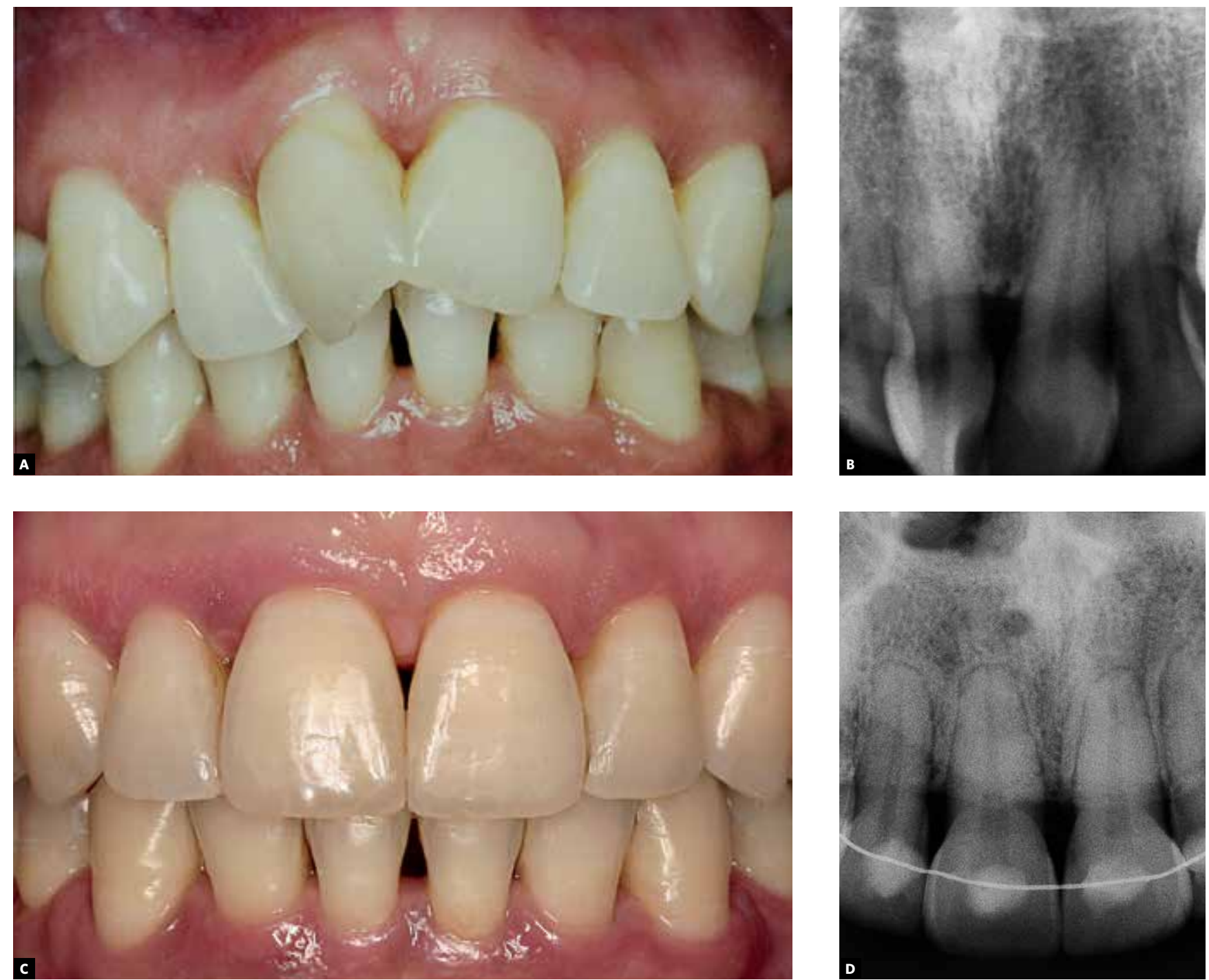

Figure 16 - Patient with history of periodontal disease, bone loss and gingival recession in upper incisor region (A, B). Reduced areas of gingival recession after retraction of upper anterior teeth $(\mathbf{C}, \mathbf{D})$.

periodontal attachment loss area (Fig 15). If these teeth are moved toward more medullary regions, the recession is more likely to improve as a result. ${ }^{2,4,13}$ In this case, the need for root coverage surgery can be determined after completion of the orthodontic treatment (Fig 16).

\section{CONCLUSIONS}

Success in definitively improving the esthetics of gingival contours requires orthodontic and peri- odontal procedures. In orthodontics, placement of corrective appliances must take into account the apical heights of the gingiva of maxillary anterior teeth. To this end, it is recommended to probe and record, for diagnostic purposes, the gingival levels prior to bonding the brackets. Knowledge of clinical periodontics should be constantly reviewed and updated to ensure that treatment is properly performed and esthetic outcomes optimized. 


\section{REFERENCES}

1. Zanetti GR, Brandão RCB, Zanetti LS, Castro GC, Borges Filho FF. Integração ortoperio-prótese para correção de assimetria gengival: relato de caso. R Dental Press Estet. 2007 Out-Dez;4(4):50-60.

2. Borghetti A. Cirurgia plástica periodontal. Porto Alegre (RS): Artmed; 2002

3. Joly JC, Silva RC, Carvalho PFM. Reconstrução tecidual estética: procedimentos plásticos e regenerativos periodontais e peri-implantares. São Paulo: Artes Medicas; 2010

4. Cohen M. Interdisciplinary treatment planning: principles, design, implementation Seattle: Quintessence; 2008.

5. Zachrisson BU. Orthodontics and periodontlcs. In: Lindh J, Karring T, Lang NP, Editors. Clinical periodontology and implant dentistry. 3rd ed. Copenhague (DK): Munksgaard; 1998. p. 741-93.

6. Kokich VO, Kokich VG, Kiyak HA. Perceptions of dental professionals and laypersons to altered dental esthetics: asymmetric and symmetric situations. Am J Orthod Dentofacial Orthop. 2006 Aug;130(2):141-51.

7. Kokich VG. Enhancing restorative, esthetic and periodontal results with orthodontic therapy. In: Schlunger S, Youdelis R, Page R, Johnson R. Editors. Periodontal Therapy. Philadelphia (PA): Lea and Febiger; 1990. p. 433-52.

8. Kokich VG, Nappen DL, Shapiro PA. Gingival contour and clinical crown length: their effect on the esthetic appearance of maxillary anterior teeth. Am J Orthod. 1984 Aug;86(2):89-94.

9. Kokich V. Esthetics and anterior tooth position: an orthodontic perspective, part II: vertical position. J Esthet Dent. 1993 Jul-Aug;5(4):174-8.

10. Kokich VG, Kokich VO, Spear F. Maximizing anterior esthetics: an interdisciplinary approach. In: McNamara JA, Kelly K Jr, editors. Frontiers in Dental and Facial Esthetics. Ann Arbor (MI): Needham; 2001.

11. Ramfjord SP. Changing Concepts in Periodontics. J Prosthet Dent. 1984 Dec;52(6):781-6

12. Ramfjord SP, Morrison EC, Burgett FG, Nissle RR, Shick RA, Zann GJ, et al. Oral hygiene and maintenance of periodontal support. J Periodontol. 1982 Jan;53(1):26-30.
13. Lindhe J. Tratado de Periodontia Clínica e Implantologia Oral. 5a ed. Rio de Janeiro: Guanabara Koogan; 2010.

14. Kokich VO Jr, Kiyak HA, Shapiro PA. Comparing the perception of dentists and lay people to altered dental esthetics. J Esthet Dent. 1999:11(6):311-24.

15. Tarnow DP, Magner AW, Fletcher P. The effect of the distance from the contact pointto the crest of bone on the presence or absence of the interproximal dental papilla. J Periodontol. 1992 Dec;63(12):995-6.

16. Fradeani M. Estethic analysis: A systematic approach to prosthetic treatment. Chicago (IL): Quintessence Books; 2004

17. Garber DA, Salama MA. The aesthetic smile: diagnosis and treatment. Periodontol 2000. 1996 Jun:11:18-28.

18. Seixas MR, Costa-Pinto RA, Araujo TM. Checklist dos aspectos estéticos a serem considerados no diagnóstico e tratamento do sorriso gengival. Dental Press $\rfloor$ Orthod. 2011 mar-abr:16(2):131-57.

19. Ericsson I, Thilander B, Lindhe J. Periodontal condition after orthodontic tooth movements in the dog. Angle Orthod. 1978 Jul;48(3):210-8.

20. Wennström JL, Lindhe J, Sinclair F, Thilander B. Some periodontal tissue reactions to orthodontic tooth movement in monkeys. J Clin Periodontol. 1987 Mar;14(3):121-9.

21. Engelking G, Zachrisson BU. Effects of incisor repositioning on monkey periodontium after expansion through the cortical plate. Am J Orthod. 1982 Jul:82(1):23-32.

22. Karring T, Nyman S, Thilander B, Magnusson I. Bone regenerations in orthodontically produced alveolar bone dehiscence's. J Periodontal Res. 1982 May;17(3):309-15

23. Wennström JL. Lack of association between width of attached gingival and development of gingival recessions. A 5-year longitudinal study. J Clin Periodontol. 1987 Mar;14(3):181-4.

24. Claffey N. Decision making in periodontal therapy: the reevaluation. J Clin Periodontal. 1991;18:384-9. 